\title{
III Congresso Sul-Brasileiro de Medicina do Esporte
}

\author{
Porto Alegre, $31 / 8$ a 2/9/2000 \\ RESUMOS DOS TEMAS LIVRES
}

\section{1 - MEDIÇÃO DO LIMIAR ANAERÓBIO EM ATLETAS DE FUTE- BOL PROFISSIONAL}

Luiz Antonio Barcellos Crescente e Félix Albuquerque Drummond Sport Club Internacional - Porto Alegre - RS

A avaliação funcional do atleta de futebol tem sido alvo de muitos estudos e trabalhos que tentam mostrar um perfil fisiológico ideal para o sua melhor performance, sendo a determinação do seu limiar anaeróbio um dos dados mais recentemente utilizados. $\mathrm{O}$ presente estudo mostra através de um teste em esteira rolante, velocidade inicial de 3 $\mathrm{m} / \mathrm{s}$ com um aumento gradativo de velocidade a cada 3 minutos de $0,5 \mathrm{~m} / \mathrm{s}$ até a exaustão, a determinação do limiar em atletas de futebol de uma equipe da primeira divisão brasileira utilizando-se para tal o método metabólico com a medição do lactato no sangue no final de cada estágio, adotando-se como limiar a velocidade correspondente a sua produção de $4 \mathrm{mmol} / \mathrm{l}$. Durante o teste a frequência cardíaca dos atletas foi também monitorizada para posterior utilização nos treinamentos. $\mathrm{O}$ quadro abaixo mostra os resultados (médias) dessas avaliações que foram realizadas duas vezes durante a temporada de 1999:

\begin{tabular}{|c|c|c|c|c|c|c|c|c|c|c|}
\hline \multicolumn{11}{|c|}{ JANEIRO (Pré-temporada) } \\
\hline Atletas & Idade & $3,5 \mathrm{n}$ & & 4,0 & & 4,5 & & F.C. máx & Limiar & F.C. limiar \\
\hline $\mathrm{N}$ & Anos & Lac & FC & Lac & FC & Lac & FC & $\mathrm{bpm}$ & $\mathrm{Km} / \mathrm{h}$ & \\
\hline 25 & 24 & 3.7 & 168 & 4.4 & 178 & 5.5 & 187 & 193 & 14.0 & 174 \\
\hline \multicolumn{11}{|c|}{$2^{\circ}$ Avaliação: JUNHO (meio da temporada) } \\
\hline Atletas & Idade & $3,5 n$ & & 4,0 & & 4,5 & & F.C. máx & Limiar & F.C. limiar \\
\hline $\mathrm{N}$ & Anos & Lac & FC & Lac & FC & Lac & FC & bpm & $\mathrm{Km} / \mathrm{h}$ & \\
\hline 28 & 24 & 3.2 & 164 & 3.7 & 174 & 4.8 & 184 & 190 & 14.8 & 175 \\
\hline
\end{tabular}

Os resultados mostram que os atletas avaliados apresentaram durante as avaliações um limiar anaeróbio que é similar aos encontrados na literatura, mostrando o acerto do trabalho desenvolvido tanto nas avaliações quanto no treinamento físico da equipe.

02 - A MEDIDA DA PRESSÃO ARTERIAL NO PRIMEIRO ESTÁGIO DO PROTOCOLO DE BALKE

Norberto Martins e Helder Santos

Grêmio Náutico União - Porto Alegre - RS

Introdução: pelo pequeno espaço de tempo entre o início da caminhada na esteira e a primeira aferição da PA no protocolo de Balke (PB), se levantou a questão da necessidade ou não de aferição da PA no primeiro estágio deste protocolo. Objetivo: verificar se existe diferença relevante e estatisticamente significativa nas medidas de pressão arterial entre o repouso e o primeiro estágio do PB nos sócios do GNU. Delineamento: coorte. Material e Método: foram analisados casos de 159 sócios submetidos ao PB. A medida da pressão arterial (PA) de repouso era realizada durante a entrevista inicial, onde, também, eram realizadas outras medidas: peso, altura, dobras cutâneas e freqüência cardíaca no repouso. A medida da PA no primeiro estágio era realizada após 1 minuto e 30 segundos do início do teste. Foi utilizado esfigmomanômetro nãoeletrônico nas aferições. Resultados: houve diferença significativa na distribuição do sexo na amostra, com predominância do sexo feminino $(65,6 \% ; \mathrm{P}=0,0001)$. A média de idade foi de $37 \pm 5,3$ anos. Em relação ao fumo, $34 \%$ dos sócios tinha história de fumo no passado e $15 \%$ eram fumantes na época do teste. O percentual de sócios com PA sistólica $\geq 140$ e/ou diastólica $\geq 90$ no repouso foi de $16,3 \%$, e em atividade física regular foi de $30,6 \%$. Houve um acréscimo médio de $9,5 \mathrm{mmHg}(\mathrm{P}<0,0001)$ na $\mathrm{PA}$ sistólica no primeiro estágio em relação à PA sistólica em repouso. A PA diastólica no primeiro estágio teve um acréscimo de $0,5 \mathrm{mmHg}(\mathrm{P}=0,241)$ em relação à PA diastólica em repouso. Conclusão: a medida da pressão arterial no primeiro estágio do protocolo de Balke é necessária, principalmente em função da variação que ocorre na pressão sistólica.

\section{3 - A PERDA DE FORÇA MUSCULAR DE MENINOS NO PERÍO-} DO DE DESTREINO

Fontoura A, Meyer F, Pinto R, Sant'Anna M, Loss FJ, Rodrigues L, Schneider P.

LAPEX - ESEF-UFRGS - Porto Alegre - RS

Os efeitos de um treinamento de força para crianças tem sido bem explorados, mas ainda existe um questionamento: $\mathrm{O}$ quanto a força decresce se a criança interrompe o treinamento? O objetivo deste estudo foi avaliar a magnitude da perda de força muscular dinâmica de 1RM de extensores da perna (EP) e flexores do braço (FB) de meninos durante o período sem o estímulo do treinamento. Seis meninos pré-púberes e púberes $(12,5 \pm 1.52$ anos) treinaram de forma dinâmica três vezes por semana por 12 semanas, entre 50 e $85 \%$ de 1RM, obtendo um ganho de força de 32,3\% nos EP e 70,3\% nos FB. Durante o período de destreino eles foram avaliados a cada 4 semanas por mais 12 semanas. O teste de $1 \mathrm{RM}$ foi realizado com uma variação de carga de $250 \mathrm{~g}$. Ao final das 12 semanas, a força de $1 \mathrm{RM}$ de EP decresceu de $17,08 \pm 2,09 \mathrm{~kg}$ para $14,13 \pm 3,15 \mathrm{~kg}$ $(\mathrm{p}<0,05)$ e na FB de $8,17 \pm 3,10 \mathrm{~kg}$ para $7,92 \pm 2,84 \mathrm{~kg}(\mathrm{p}=0,376)$. Quando corrigida pelo peso corporal, o padrão da perda de força não foi modificado. Os resultados mostraram que durante as 12 semanas de destreino, os meninos perderam significativamente a força de 1RM apenas em EP. Este resultado pode ser devido ao diferente grau de treinabilidade entre os segmentos. O maior ganho de força ocorrido nos membros superiores com este treinamento, parece amenizar a perda de força, proporcionando por mais tempo os ganhos obtidos com o treinamento. Apoio CNPq.

\section{4 - ANÁLISE MORFOLÓGICA EM CRIANÇAS QUE PRATICAM A GINÁSTICA OLÍMPICA FEMININA}

João Carlos Oliva, Rafael Reimann Baptista, Djan Drago e Maive Furman Universidade Luterana do Brasil - Canoas - RS

O objetivo deste estudo foi analisar a influência do treinamento sistemático de Ginástica Olímpica nas variáveis antropométricas e de composição corporal em crianças do sexo feminino. As participantes foram selecionadas de forma intencional e divididas em dois grupos: Atletas do Campeonato Brasileiro de Ginástica Olímpica, nos anos de 1995, 1996 e 1997 (grupo das ginastas) e crianças que não praticaram nenhum esporte competitivo nos mesmos anos (grupo das não atletas). A metodologia utilizada foi desenvolvimentista com um delineamento transversal de comparação entre grupos. As variáveis antropométricas analisadas foram massa corporal, estatura, comprimento tronco-cefálico e comprimento de membros inferiores, a composição corporal foi medida através de protocolo de dobras cutâneas. Para o tratamento estatístico das variáveis, recorreu-se ao teste " $\mathrm{t}$ " de Student para amostra independente, através do software SPSS for Windows (versão 8.0). Os resultados encontrados demonstraram que: a) a massa corporal apresentou valores significativamente maiores no grupo das não atletas; b) a estatura e o comprimento tronco-cefálico apresentaram similar proporção em ambos os grupos; c) o comprimento dos membros inferiores foi superior no grupo das não atletas; d) os indicadores da composição corporal revelaram resultados alternados nos valores médios de gordura corporal, entre os grupos, com uma tendência de apresentar valores mais elevados para o grupo das não atletas; Pode-se inferir que o grupo das ginastas apresentou características de menor estatura e percentual de gordura em relação ao grupo das não atletas, e essas características aparentemente, não são definidas pelo treinamento sistemático, mas sim por uma seleção natural da modalidade.

05 - EVOLUÇÃO DO GANHO DE FORÇA ATRAVÉS DE EXERCÍCIOS EM CADEIA CINÉTICA ABERTA E FECHADA NA REABILITAÇÃO CIRÚRGICA DO LIGAMENTO CRUZADO ANTERIOR

Cláudia Silveira Lima e Antonio Carlos Stringhini Guimarães

Centro INDESP/UFRGS de Excelência Esportiva - Laboratório de Pesquisa do Exercício (LAPEX). Escola de Educação Física (ESEF) - Universidade Federal do Rio Grande do Sul (UFRGS) - Porto Alegre - RS

$\mathrm{O}$ ganho de força muscular é semelhante ao compararmos protocolos de reabilitação em cadeia cinética aberta (CCA) e fechada (CCF) em indivíduos submetidos a cirurgia de ligamento cruzado anterior (LCA) (Lima, C.S. e Guimarães, A.C.S., 1999). O aumento de força muscular, ao longo do tempo, entretanto, pode ocorrer de forma mais rápida num tipo de exercício do que no outro, embora o resultado final possa ser semelhante. Exercícios em CCA foram comparados a exercícios em CCF, em relação a evolução da força muscular de extensores e flexores do joelho após cirurgia de LCA. Dez sujeitos (idade entre 18- 40 anos; sexo masculino e feminino) foram divididos em dois grupos de cinco $(\mathrm{n}=5)$. Um grupo realizou exercícios em CCA e o outro em CCF. $\mathrm{O}$ torque produzido pelos extensores e flexores do joelho foram determinados através do dinamômetro isocinético CYBEX Norm, no início, e após o primeiro, segundo e terceiro mês de tratamento. Foram realizadas três sessões semanais de exercícios em CCA ou CCF, durante 12 semanas. No grupo que realizou CCA, os resultados obtidos demonstraram diferença significativa $(\alpha=0.05)$ entre os valores iniciais com cada uma das outras três medidas para os extensores do joelho. Em relação aos flexores, somente na comparação do primeiro para o segundo mês não houve diferença signifi- 
cativa. No grupo que realizou CCF, apenas os extensores do joelho apresentaram aumento significativo, e só ao compararmos os valores inicias com os finais. Estes resultados sugerem que os exercícios em CCA aumentam a força muscular de forma mais rápida e gradual do que em CCF. Entretanto, decorridos três meses de tratamento os valores atingidos são semelhantes nos dois tipos de programas.

\section{O6 - AVALIAÇÃO DO PADRÃO MENSTRUAL DE UM GRUPO DE ATLETAS DE FUTEBOL}

Geraldo Gomes da Silveira; Andréia Beatriz Silva dos Santos e Charles Luciano Genehr

FFFCMPA - Porto Alegre - RS

Introdução: Algumas mulheres que treinam em altas intensidades têm um risco maior de apresentar oligomenorréia e amenorréia secundária. Tais patologias foram encontradas em um estudo realizado em atletas levantadoras de peso, com prevalências de $20 \%$ e $2 \%$, respectivamente, naquelas que não estivessem tomando anticoncepcionais orais; $25 \%$ relataram menstruações irregulares. Entre mulheres sedentárias a prevalência encontrada foi de $9 \%$ e $4 \%$, respectivamente. Os mecanismos fisiológicos responsáveis pelo desenvolvimento das alterações menstruais ainda não estão totalmente esclarecidos. Objetivos: Estudar a prevalência de alterações menstruais das atletas de futebol e relacionar com fatores associados como: intensidade, duração, frequiência, história nutricional e overtraining. População e Métodos: População era composta por atletas de futebol feminino sendo a amostra de 38 atletas do Grêmio Football Porto-Alegrense, entre 13 e 33 anos, que treinavam 5 dias por semana, 3 horas por dia. Foi realizado um estudo transversal através da aplicação de questionários. Resultados e Conclusão: A média de idade foi de 17,89 anos e 76,31\% eram brancas. Entre as pesquisadas $73,65 \%$ praticavam futebol 3 horas por dia, 5 dias por semana há pelo menos 2 anos. Nenhuma atleta fazia uso de anticoncepcional oral. O ciclo menstrual irregular foi referido por $55,26 \%$ das atletas. A prevalência de oligomenorréia foi de $23,68 \%$ e amenorréia secundária, $2,63 \%$. Insônia, falta de apetite e fadiga crônica (sugerindo overtraining) foram referidos por $22,22 \%$ das atletas com oligomenorréia. Neste caso, é fundamental uma abordagem multidisciplinar (médico do esporte, nutricionista, preparador físico, psicólogo) para acompanhamento da atleta, contribuindo para a manutenção da unidade atleta-saúde.

\section{O7 - COMPARAÇÃO ENTRE SOMATOTIPO DE JOGADORES DE} FUTEBOL

José Leandro Nunes de Oliveira e João Ricardo Turra Magni

Grêmio Football Porto-Alegrense - Porto Alegre - RS

O objetivo do presente estudo foi estabelecer uma relação entre a configuração morfológica de diferentes categorias (categoria 87: $\mathrm{N}=34$ - 13 anos, categoria 86: $\mathrm{N}=31-14$ anos, infantil: $\mathrm{N}=38-15$ anos, juvenil: $\mathrm{N}=43-16,34 \pm 0,48$ anos, juniores: $\mathrm{N}=31-$ $18,73 \pm 0,83$ anos e profissionais: $\mathrm{N}=41-25,14 \pm 4,7$ anos) praticantes de futebol de campo. Foram determinados: o peso corporal total em kg através de uma balança "To-

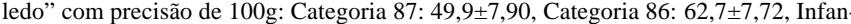
til: $65,6 \pm 5,36$, juvenil: $70,7 \pm 5,68$, Juniores: $72,9 \pm 6,66$ e profissional: $76,39 \pm 5,694$,

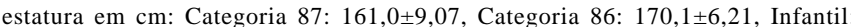
175,7 $\pm 5,128$, juvenil: $178,0 \pm 6,40$, Juniores: $179,6 \pm 6,67$ e, profissional: $180,01 \pm 5,74$, com estadiômetro Cescorf - precisão de $1 \mathrm{~mm}$. O somatotipo foi estimado através do método antropométrico de Heath-Carter - categoria 87: 2,5 $\pm 0,94-4,7 \pm 0,75-3,5 \pm$ 0,95 ; categoria $86: 2,3 \pm 0,52-5,0 \pm 0,84-2,8 \pm 0,96$; infantil: $2,1 \pm 0,45-4,7 \pm 0,75-$ $3,3 \pm 0,86$; juvenil: $1,9 \pm 0,39-4,9 \pm 1,12-3,0 \pm 0,90$; júnior: $2,0 \pm 0,54-4,6 \pm 1,00-$ $2,9 \pm 0,73$ e profissional: $2,2 \pm 0,55-4,9 \pm 0,74-2,5 \pm 0,83$. Quanto ao componente Endo, observa-se um decréscimo com o aumento da faixa etária até a categoria juvenil. A partir da categoria júnior tem-se, com a estabilidade da curva de estatura, uma elevação no componente Endo. Observa-se uma forte semelhança entre as características morfológicas quanto ao componente Meso nas diferentes categorias estudadas. O componente Ecto decresce a medida em que avança a faixa etária, com uma menor linearidade relativa nas categorias mais velhas, exceto na categoria 86 .

O8 - ESTUDO COMPARATIVO ENTRE O TESTE DO BANCO DE WELLS E A INCIDÊNCIA DE LOMBALGIA EM ATLETAS DAS CATEGORIAS DE BASE DO SPORT CLUB INTERNACIONAL

Emerson Luís Dias Tavares, Feliciano Bastos Neto, Wagner da Silva Pessopani

Sport Club Internacional - Porto Alegre - RS

Introdução: $\mathrm{O}$ futebol é uma forma prazerosa de praticar exercício e promover saúde. Com um número acentuado de praticantes apresenta um alto índice de lesões. Uma delas é a lombalgia. Com o intuito de verificar correlação entre lombalgia e flexibilidade lombar o presente estudo mostra a aplicação do teste de "sentar e alcançar" em futebolistas comparando o resultado obtido no teste e o número de casos de lombalgia de março a setembro de 1999 no departamento de futebol amador do Sport Club Internacional. Objetivo: Verificar a incidência de lombalgia nos atletas das categorias de base do Sport Club Internacional através do teste do Banco de Wells. Material e Métodos: Serviram como objeto de estudo 88 atletas das categorias infantil, juvenil e júnior, todos do sexo masculino pertencentes ao departamento de futebol amador do Sport Club Internacional. A flexibilidade foi avaliada através do teste "sentar e alcançar" idealizado por Wells e Dillon e modificado por Camaione (1980). Basicamente o teste objetivou medir a flexibilidade de tronco/quadril e musculatura de membros inferiores na posição sentada. Posteriormente calculou-se a média aritmética das três tentativas e do grupo. Resultados: Dos 88 atletas avaliados, 10 apresentaram lombalgia o que correspondeu a $11,36 \%$ do total do grupo. Observamos que fatores emocionais, frequiência e erros de treinamento, condicionamento físico inadequado colaboram para a ocorrência de lombalgia. Constatamos a importância da flexibilidade para futebolistas. Conclusão: O baixo índice de lombalgia mostrou o bom trabalho do departamento médico do clube onde existe um caráter interdisciplinar e o fisioterapeuta atua de forma preventiva junto ao atleta. Concluímos que a flexibilidade é um parâmetro fisiológico relativo, e que flexibilidade ideal é a que permite o atleta realizar atividade sem limitação funcional.

\section{9 - ESTUDO DA ATIVIDADE FÍSICA NA GESTAÇÃO - UM EN- SAIO CLÍNICO RANDOMIZADO.}

Iracema Athayde Santos, Cristiane G. Borba, Michelle Lavinsky, Gustavo José Somm, Luciano Isolan, Carolina Alboim, José Geraldo Ramos, Maria Lúcia Oppermann, Sandra Costa Fuchs, Bruce B. Duncan, Maria Inês Schmidt

Departamento de Medicina Social, Faculdade de Medicina, UFRGS - Porto Alegre - RS

Introdução: As gestantes obesas apresentam um risco maior que as não obesas de diabetes gestacional, hipertensão gestacional, pré-eclâmpsia, pós-datismo, trabalho de parto prologado, distócia, parto cesariana e macrossomia. Além disso, o peso maior ao nascer é um fator de risco para obesidade na infância e na vida adulta. Apesar desses riscos, intervenções específicas para a gestante obesa são muito restritas. Embora a literatura ainda seja controversa, estudos clínicos recentes sugerem que gestantes que fazem exercício físico durante a gravidez apresentam menor ganho de peso e menor gordura subcutânea, menor risco de desenvolver diabetes gestacional, redução da duração de trabalho de parto e da incidência de macrossomia fetal. Objetivos: Demonstrar a eficácia da atividade física na gravidez para o controle do ganho de peso materno e fetal e de outros desfechos adversos da gravidez a eles relacionados. Material e Métodos: O estudo é um ensaio clínico randomizado, com 30 gestantes em cada um dos dois braços, sendo a intervenção um programa específico de atividade física e o controle apenas o cuidado pré-natal convencional. Os critérios de inclusão incluem: história negativa de diabetes pré-gestacional e fumo atual e história de cessação de fumo há menos de 1 ano; índice de massa corporal pré-gravídico entre 25 e $30 \mathrm{~kg} / \mathrm{m}^{2}$; idade gestacional < 20 semanas; consentimento informado; adesão ao protocolo estabelecido no período run in. A randomização será feita em blocos no tempo. As aferições serão realizadas na triagem, no arrolamento, no período pré-natal, no parto e no período pós-parto. Os desfechos da gestante são ganho de peso na gravidez, aumento da massa de gordura corporal e elementos da síndrome metabólica. Os desfechos do recém-nascido são peso e ponderosidade ao nascer, massa de gordura corporal e insulina/glicose em sangue do cordão umbilical. Resultados esperados: Demonstrar a eficácia de programa de atividade física com base na melhora de desfechos substitutos. Repercussões possíveis: esses dados de eficácia podem subsidiar recomendações obstétricas com base em evidências intermediárias; além disso poderão servir de justificativa para ensaio clínico randomizado maior, com desfechos clínicos de significado real ao paciente. (CNPq-PIBIC/UFRGS).

\section{0 - FREQÜÊNCIA DE TREINAMENTO FÍSICO E ESTRESSE OXI- DATIVO CARDÍACO}

Souza-Rabbo, M.P; Fernandes, T.R; Llesuy, S; Belló A. A; Belló-Klein, A. Lab. de Fisiologia Cardiovascular, Dep. de Fisiologia, UFRGS - Porto Alegre - RS

Introdução: o exercício físico, mesmo benéfico, pode trazer prejuízos a seus praticantes. Muitos destes, induzidos pelo aumento das espécies ativas de oxigênio (EAO), sem a devida adaptação do sistema de defesa celular antioxidante. Objetivos: verificar os efeitos de diferentes frequiências de exercício físico na lipoperoxidação (LPO) e atividade das enzimas antioxidantes, Glutationa peroxidase (GPx) e Superóxido Dismutase (SOD), em coração de rato. Materiais e métodos: 22 ratos Wistar, machos, divididos em 4 grupos: Controle (GC), sem exercício; Sedentário (GS), 1 única sessão no final do protocolo; Treinado agudo (GTA), $1 \mathrm{X}$ por semana: Treinado crônico (GTC), $5 \mathrm{X}$ por semana. Treinamento em esteira ergométrica, durante $1 \mathrm{~h}$, a $60 \%$ do $\mathrm{VO}_{2}$ máx., 
durante 13 semanas. Os animais foram mortos imediatamente após o término do protocolo. Para as medidas de LPO (por quimiluminescência), GPx, e SOD, (por espectrofotometria), foram utilizados homogeneizado do tecido cardíaco. Resultados: a QL (cps/mg prot.), foi maior no GS e no GTA, em relação aos GC e GTC. O GTC mostrou atividade da SOD aumentada ( $11,2 \pm 0,9 \mathrm{U} / \mathrm{mg}$ prot.) em relação aos GC $(9,0$ $\pm 0,4)$, GS $(9,8 \pm 1,4)$ e GTA $(10,5 \pm 0,7)$. A atividade da GPx (nmol $/ \mathrm{min} / \mathrm{mg}$.prot.), foi maior no GTA (347,6 \pm 7$)$, em relação aos demais grupos, GC (247 \pm 12$)$, GS (276,8 \pm 27) e GTC (280,6 \pm ). Conclusão: os resultados sugerem que o exercício crônico promove adaptação do sistema antioxidante e diminui a LPO, não ocorrendo com exercícios de baixa freqüência.

\section{1 - FORÇA ESTÁTICA E ISOCINÉTICA DE MENINAS E MENI- NOS PÚBERES}

Luciana Rodrigues, Patrícia Schneider, Andréa Fontoura e Flávia Meyer Escola de Educação Física - UFRGS - Porto Alegre - RS

$\mathrm{Na}$ puberdade, os meninos são mais fortes do que as meninas, em parte devido as diferenças de massa corporal. O objetivo deste estudo é examinar a força muscular de meninas e meninos púberes. Foram avaliados 16 meninas $(11,5 \pm 1,2$ anos e 38,3 \pm 7,6 $\mathrm{kg})$ e 14 meninos $(12,6 \pm 1,7$ anos e 47,4 $\pm 11,9 \mathrm{~kg})$ saudáveis, não atletas e púberes conforme Tanner. Um dinamômetro computadorizado (Cybex Norm) foi usado para medir a força estática (ângulo $=60^{\circ}$ ) e isocinética (velocidade $=60^{\circ} / \mathrm{s}$ ) da extensão de pernas e flexão de braço. Os resultados (média \pm dp) absolutos $(\mathrm{Nm})$ e corrigidos pela massa corporal $(\mathrm{Nm} / \mathrm{kg})$ estão mostrados na tabela.

\begin{tabular}{|c|c|c|c|c|c|}
\hline \multicolumn{2}{|c|}{} & \multicolumn{2}{|c|}{ Pernas } & \multicolumn{2}{c|}{ Braços } \\
\hline \multirow{3}{*}{ Absoluto } & & Estático & Isocinético & Estático & Isocinético \\
\cline { 2 - 6 } & Meninas & $105,5 \pm 24,5$ & $65,4 \pm 18,5$ & $19 \pm 5,4$ & $11,9 \pm 3,7$ \\
\cline { 2 - 6 } & Meninos & $141,8 \pm 34,7$ & $87,6 \pm 29,6$ & $28,4 \pm 8,6$ & $18,6 \pm 8,3$ \\
\hline \multirow{2}{*}{ Relativivo } & Meninas & $2,75 \pm 0,2$ & $1,7 \pm 0,3$ & $0,5 \pm 0,1$ & $0,31 \pm 0,09$ \\
\cline { 2 - 6 } & Meninos & $3 \pm 0,6$ & $1,84 \pm 0,4$ & $0,6 \pm 0,16$ & $0,4 \pm 0,15$ \\
\hline
\end{tabular}

Os resultados ilustram que quando a força é corrigida pela massa corporal a magnitude da diferença entre meninos e meninas púberes diminui. Apoio CNPq.

\section{2 - PERFIL ANAERÓBIO DE DIFERENTES MODALIDADES ES- PORTIVAS UTILIZANDO UM NOVO TESTE DE CAMPO}

Marcelo Cardoso, Osvaldo D. Siqueira e Luiz A. Crescente

LAPEX/ESEF/UFRGS - Porto Alegre - RS; LAFIMED/ULBRA - Canoas - RS

Para os profissionais que trabalham com treinamento esportivo é importante conhecer o desempenho anaeróbio dos seus atletas. Bar-Or em seus estudos sugere um teste para avaliar essa variável relacionada com a performance, o Wingate Anaerobic Test. No entanto, a utilização deste teste para atletas onde a corrida é a base do movimento, não atende a sua especificidade, pois sua execução é realizada através do ato de pedalar. $\mathrm{O}$ presente estudo tem por objetivo apresentar o perfil anaeróbio de diferentes modalidades esportivas utilizando um novo teste, R.A.S.T., (Running-based Anaerobic Sprint Test), bem como, compará-los aos resultados de outras investigações. O instrumento de medida consiste em correr 6 vezes a distância de 35 metros na maior velocidade possível com um intervalo entre cada deslocamento de 10 segundos. O quadro abaixo apresenta a amostra avaliada e os resultados do perfil em médias e desvios padrão:

\begin{tabular}{|c|c|c|c|c|c|c|c|}
\hline Modalidades & $\mathrm{N}$ & \multicolumn{2}{|c|}{ Potência máxima $(\mathrm{W} / \mathrm{Kg})$} & \multicolumn{2}{|c|}{ Potência média $(\mathrm{W} / \mathrm{Kg})$} & \multicolumn{2}{|c|}{$\begin{array}{c}\text { Potência minima } \\
\text { (W/Kg) }\end{array}$} \\
\hline & & Média & $\begin{array}{c}\text { Desvio } \\
\text { padrăo }\end{array}$ & Média & $\begin{array}{c}\text { Desvio } \\
\text { padrăo }\end{array}$ & Média & $\begin{array}{c}\text { Desvio } \\
\text { padrão }\end{array}$ \\
\hline Futebol (adulto) & 95 & 10,62 & 1,36 & $\mathbf{8 , 6 3}$ & $\mathbf{1 , 0 5}$ & 7,03 & 1,08 \\
\hline Futebol (júnior) & 25 & 10,70 & 0,99 & $\mathbf{8 , 0 1}$ & 0,65 & 5,85 & $\mathbf{0 , 7 7}$ \\
\hline Futebol (juvenil) & 24 & 10,40 & 0,82 & 7,84 & 0,79 & 6,05 & $-0,79$ \\
\hline Futsal (adulto) & 24 & 9,88 & 1,39 & 7,99 & 1,03 & 6,38 & 1,15 \\
\hline Voleibol (juvenil) & 15 & 8,61 & 1,03 & 7,13 & 0,83 & 5,73 & 0,80 \\
\hline
\end{tabular}

Na comparação dos índices médios do trabalho com o índice de outros estudos utilizamos o teste "T" para uma amostra. Os perfis apresentados acima quando comparados aos encontrados na literatura existente, não apresentaram diferenças significativas, $\mathrm{p}>$ 0,05, evidenciando que o R.A.S.T. pode ser utilizado na avaliação anaeróbia de atletas que utilizam a corrida como base do seu movimento. Pela facilidade de aplicação e pela qualidade dos resultados, esse teste proporciona relevantes informações para a planificação e condução no processo do treinamento esportivo.

\section{3 - ESTUDO ANTROPOMÉTRICO COMPARATIVO ENTRE ME-} NINAS PRATICANTES DE DANÇA DE UMA CIDADE ESPANHOLA E MENINAS PRATICANTES DE DANÇA DE UMA CIDADE BRASILEIRA

Aline Nogueira Haas, Manuel Rosety Plaza, M. e Eduardo Henrique De Rose Departamento de Educação Física, Faculdade de Educação Física, Universidade Luterana do Brasil - Canoas - RS; Departamento de Ciências Morfológicas, Faculdade de Medicina, Universidade de Cádiz - Cádiz-Espanha; Departamento de Desportos, Escola de Educação Física, Universidade Federal do Rio Grande do Sul - Porto Alegre $-R S$.

Resumo: Pouco se sabe a respeito da influência da dança no desenvolvimento morfológico e antropométrico de meninas e adolescentes - meninas-bailarinas -, tendo-se grande dificuldade de encontrar estudos realizados acerca de populações desse tipo. O objetivo desse estudo foi analisar, por meio de um estudo comparativo, as características antropométricas de uma população de meninas-bailarinas pertencentes à cidade de Porto Alegre (RS), Brasil, praticantes de ballet clássico, idade média $11.12 \pm 1.00$, e à cidade de Córdoba (CO), Espanha, praticantes de ballet clássico e dança espanhola, idade média $11.50 \pm 0.94$, estabelecendo um paralelismo entre estas duas populações comparando e relacionando os dados obtidos. Foram medidas 50 variáveis antropométricas (incluindo peso corporal, envergadura, estatura, alturas, perímetros, dobras cutâneas, diâmetros e longitudes), utilizando o método antropométrico, baseado no protocolo da "International Society of the Advancement of Kinanthropometry", proposto por ROSS e MARFELL-JONES em 1991. Utilizou-se a metodologia estatística descritiva, para obter um banco de dados das duas amostras estudadas, e o teste da diferença entre as médias ("Teste t"), para comparar os dados obtidos entre as duas populações, verificando se existiam diferenças significativas entre as mesmas $(\mathrm{p}<0.05)$. As diferenças estatísticas encontradas foram no diâmetro biepicondiliano do úmero (5.57 \pm 0.33 , cordobesas, e $5.88 \pm 0.38$, porto-alegrenses), no diâmetro biestilóide ( $4.51 \pm 0.25$, cordobesas, e $4.75 \pm 0.28$, porto-alegrenses), na largura da mão $(6.97 \pm 0.41$, cordobesas, e $7.68 \pm 4.14$, porto-alegrenses) e no diâmetro bimaleolar $(6.44 \pm 0.33$, cordobesas, e 6.64 \pm 0.40 ,porto-alegrenses). Através da análise dos resultados obtidos concluiu-se que os dois grupos estudados são muito semelhantes, ainda que encontradas algumas variáveis com diferenças estatísticas.

\section{4 - AVALIAÇÃO DO USO DE TRÊS DIFERENTES TIPOS DE TRA TAMENTO FARMACOLÓGICO NA ENTORSE DE TORNOZELO EM ATLETAS}

Ivan Pacheco, Helder Fernando dos Santos, Rosemary Petkowicz, Adriana Moré Pacheco, Gordon Bock

Grêmio Náutico União - Porto Alegre - RS

Introdução: A entorse de tornozelo é a lesão mais comum na prática de esporte. Ela chega a ser $25 \%$ de todas as lesões em muitos esportes. Tradicionalmente, a entorse de tornozelo é classificada na prática como grau I (leve), grau II (moderada) e grau III (severa). Existe uma grande variação na maneira de, tratar e reabilitar esta lesão. Autores mostraram que a mobilização precoce e controlada deve ser o tratamento de escolha e produz uma recuperação, sem prejuízos, e retorno rápido ao esporte, porém esta abordagem nem sempre é a de escolha, mesmo em atletas. Objetivos: Comparar 3 tipos de farmacoterapia na entorse de tornozelo grau II associados a crioterapia, imobilizador e uso de muletas quando necessário. Material e Métodos: Os autores avaliaram um manejo inicial das entorses graus II, nos atletas do Grêmio Náutico União e Esporte Clube São José de Porto Alegre que consistiu no uso de imobilizador removível, crioterapia e analgesia ou anti-inflamatório tópico ou via oral. Foram estudados, 45 casos de entorse de tornozelo grau II, em atletas (divididos em 3 grupos de 15 cada). A avaliação e o seguimento foram realizados para os quesitos dor, mobilidade, apoio e edema nos dias primeiro, 3, 5 e 7 da seguinte forma. DOR: Foi avaliada através de uma nota dada pelo atleta. No primeiro dia a nota era 10 para todos os avaliados. MOBILIDADE: Foi classificada em 4 graus sendo $\mathrm{A}=100 \%, \mathrm{~B}=75 \%, \mathrm{C}=50 \%$ e $\mathrm{D}=$ $25 \%$, medida passivamente, com goniômetro, comparando com o lado não afetado. APOIO: O apoio foi registrado de acordo com o número de passos que o atleta conseguia dar a cada dia da avaliação. EDEMA: Foi medido em centímetros nos dois maiores extremos e após calculada uma média deste dois extremos. No primeiro grupo foi ministrado diclofenaco $50 \mathrm{mg}$ a cada 8 horas durante 5 dias. No segundo grupo foi aplicado adesivo com flurbiprufeno (Targus ${ }^{\circledR}-$ Knoll) a cada 12 horas durante 5 dias. Para o terceiro grupo a medicação foi paracetamol $1,5 \mathrm{~g}$ de $6 / 6$ horas durante 5 dias. A crioterapia foi aplicada, 20 minutos 6 vezes por dia. O uso do imobilizador era descontinuado apenas para a aplicação da crioterapia e banho diário e o uso de bengalas foi utilizado de acordo com a tolerância dos atletas em apoiar o tornozelo acometido. Resultados: O parâmetro dor nos dias 3, 5 e 7 mostraram uma diferença estatísticamente significativa para o grupo do paracetamol $(\mathrm{p}<0,05)$, no teste de Kruskal-Wallis. O grupo que utilizou diclofenaco via oral é que apresentou uma diferença significativa $(\mathrm{p}<0,05)$ quando o edema foi o parâmetro, até $5^{\circ}$ dia. No sétimo dia não houve diferença. As outras avaliações não mostraram diferenças significativas entre os grupos. Conclusões: $O$ uso de anti-inflamatório é eficaz até o $5^{\circ}$ dia da entorse do tornozelo e o seu uso após não difere da analgesia simples. Em pacientes com distúrbios gastro-intestinais ou alergias aos AINES, o uso de crioterapia e paracetamol pode ser usado e é eficaz para o tratamento inicial da entorse de tornozelo. 


\section{5 - PERFIL MORFOFUNCIONAL DE ADVOGADOS QUE REALI- ZAM ATIVIDADE FÍSICA ORIENTADA}

Adriano Rocha, Daniel Feio, Doralice Pol, Edeloni da Silva, Elenara Dias, Janaina Mello, Rafael Baptista, Regina Souza, Vinícius Ferreira.

Universidade Luterana do Brasil - Canoas - RS

A rotina diária de nossa sociedade vem tornando-se cada vez mais estressante, isso fica bastante claro em algumas classes profissionais específicas, como no caso da classe Jurídica. O presente estudo objetivou definir o perfil morfofuncional de Bacharéis em Direito, antes de ingressarem em um programa de Atividade Física Orientada, em um centro destinado a atender este grupo. A amostra investigada foi composta por 69 advogados dentro de uma faixa etária entre 22 a 81 anos de idade em ambos sexos. Foram analisadas as variáveis: Peso, Estatura, Composição Corporal por protocolo de dobras cutâneas, Pressão Arterial e Avaliação Postural. A análise dos dados foi feita através de estatística descritiva utilizando o software SPSS for Windows, versão 8.0. Os resultados mostraram que a grande maioria dos avaliados encontrava-se acima dos níveis desejados de gordura corporal, apresentavam desvios posturais especialmente nas regiões da Cintura Escapular, Coluna Dorsal e Musculatura Posterior da Coxa e o quadro de Pressão Arterial dentro da normalidade. Conclui-se que tais resultados estão intimamente correlacionados com os hábitos de vida destes profissionais, com exceção dos níveis de Pressão Arterial os quais sofrem forte influência genética.

\section{6 - LEVANTAMENTO DE INCIDÊNCIA DE LESÕES NOS ATLE-} TAS AMADORES DO GRÊMIO FUTEBOL PORTO ALEGRENSE

Bastos, Feliciano; Dias, Luciano; Moussalle, Mauren

Grêmio Football Porto-Alegrense - Porto Alegre - RS

Devido ao aumento da competitividade apresentada pelo futebol nos últimos anos, os praticantes desta modalidade tiveram que se adaptar às exigências impostas pela mesma, ocorrendo com isso uma diminuição da saúde, causando desgastes físicos e emocionais, levando a uma maior predisposição a lesões. O presente trabalho descreveu as lesões que mais acometeram os atletas da categoria amadora do Grêmio Futebol Porto Alegrense, relacionando-as com as posições táticas, tempo de permanência no Departamento Fisioterapêutico e local anatômico afetado. Foi observado, uma amostra de 153 atletas do sexo masculino, no período de março de 1998 a maio de 1999, através de coleta diária de dados, na qual obtivemos um total de 128 lesões. Constatou-se então, que de todas as posições táticas, os meio-campistas e atacantes tiveram uma incidência maior a lesões, mostrando que a patologia mais acometida foi o entorse, seguido de lesões tendíneas e contusão. O tempo de permanência no Departamento de Fisioterapia, teve a média de 37 dias, impossibilitando a prática do esporte por estes atletas. Os segmentos anatômicos mais afetados estiveram relacionados com os MsIs (joelho e tornozelo). Concluímos então que na análise feita, há uma variação de tipos de lesões nas determinadas posições táticas, mostrando também que o tempo de permanência na Fisioterapia e o local anatômico dependem do grau da lesão ocorrida e função exercida dentro de campo.

\section{7 - PROGRESSÃO DA FORÇA MUSCULAR EM MENINOS A PAR- TIR DA PRÉ -PUBERDADE}

Patrícia Schneider, Luciana Rodrigues, Andréa Fontoura e Flávia Meyer

Escola de Educação Física - UFRGS - Porto Alegre - RS

$\mathrm{O}$ aumento da força muscular na puberdade ocorre devido ao pico de crescimento somático e muscular. O objetivo deste estudo é de examinar a progressão da força muscular em meninos desde a fase pré-púbere. Um total de 41 meninos saudáveis e não atletas foram divididos, conforme Tanner, em 5 grupos: pré-púberes (G1P1, n= 7), púbere inicial ( $\mathrm{G} 2 \mathrm{P} 1, \mathrm{n}=15)$, púbere intermediário $(\mathrm{G} 2 \mathrm{P} 2$ a G3P3, n=10), púbere final (G4P3 a G4P4, n=4), e pós-púbere (G5P5, n=5). Foi usado um dinamômetro computadorizado (Cybex Norm), para medir a força estática da extensão de joelhos e flexão de cotovelo em 60 graus; e a força isocinética concêntrica dos mesmos movimentos na velocidade de 60 graus/segundo. Os resultados em Nm (média \pm dp) estão mostrados na tabela.

\begin{tabular}{c|c|c|c|c|c} 
Variável & Idade & Est. Perna & Est. Braço & Isoc. Perna & Isoc. Braço \\
\hline G1 & $9,0 \pm 1,0$ & $85,3 \pm 28,5$ & $17,2 \pm 4,8$ & $51,2 \pm 17,9$ & $10,2 \pm 5,3$ \\
\hline G2 & $9,5 \pm 1,5$ & $92,6 \pm 28,8$ & $17,4 \pm 5,2$ & $63,4 \pm 21,2$ & $11,3 \pm 4,6$ \\
\hline G3 & $12,2 \pm 1,7$ & $133,0 \pm 28,1$ & $26,4 \pm 8,0$ & $80,2 \pm 24,7$ & $18,3 \pm 8,0$ \\
\hline G4 & $13,5 \pm 1$ & $163,7 \pm 44,0$ & $33,2 \pm 9,2$ & $106,0 \pm 36,5$ & $19,5 \pm 9,9$ \\
\hline G5 & $13,6 \pm 0,5$ & $173,8 \pm 30,4$ & $41,2 \pm 9,6$ & $118,2 \pm 36,4$ & $32,8 \pm 6,9$
\end{tabular}

Os resultados ilustram um aumento progressivo e significativo da força muscular estática e isocinética, à medida que os meninos maturam.

\section{$\overline{18 \text { - COMPOSIÇÃO CORPORAL DE ATLETAS ESTREANTES DE }}$} FISICULTURISMO

Rafael de Souza Trindade e Paulo Rodrigo Pedroso da Silva

Curso de Pós Graduação em Ciências e Medicina do Esporte 2000 -PUC - Porto

Alegre - RS

$\mathrm{O}$ trabalho foi realizado durante a pesagem dos sete atletas participantes do campeonato gaúcho de estreantes em fisiculturismo, no dia $1^{\circ}$ de julho de 2000 , realizada em uma academia de Porto Alegre- RS. Os atletas foram submetidos à avaliação antropométrica, realizada com plicômetro científico, paquímetro, estadiômetro e balança, que incluiu as seguintes medidas: massa, estatura, diâmetros biestilóide e femural, dobras cutâneas subescapular, triceptal, biceptal, peitoral, axilar média, abdominal e coxa. Os dados foram submetidos ao protocolo de Jackson e Pollock, de 1978, de 18 a 61 anos, obtendo dados de peso muscular, residual e ósseo, além do percentual de gordura, este analisado posteriormente segundo dados da OMS, e comparados com a literatura. O maior percentual de gordura encontrado foi de $11,21 \%$ e o menor foi $5,09 \%$.

\section{9 - ANALISE ANTROPOMÉTRICA EM CRIANÇAS QUE PRATI- CAM GINÁSTICA OLÍMPICA FEMININA}

João C. Oliva, Djan Drago, Rafael Baptista, Maive Furman

Universidade Luterana do Brasil - Canoas - RS

O objetivo do estudo foi analisar variáveis antropométricas em crianças, do sexo feminino. Os participantes foram selecionados de forma intencional e divididos em dois grupos: Atletas do Campeonato Brasileiro de Ginástica Olímpica, nos anos de 1995, 1996 e 1997 (grupo das ginastas) e crianças que não praticaram de nenhum esporte competitivo nos mesmos anos (grupo das não atletas). A metodologia utilizada foi desenvolvimentista com um delineamento transversal de comparação entre grupos. As variáveis antropométricas analisadas foi massa corporal, estatura, comprimento tronco-cefálico e comprimento de membros inferiores. Para o tratamento estatístico das variáveis, recorreu-se ao teste " $\mathrm{t}$ " de Student para amostra independente, através do software SPSS for Windows (versão 8.0). Os resultados encontrados deixou claro que: a) o peso corporal em todas as idades, apresentou valores significantes maiores no grupo das não atletas; b) a estatura e o comprimento tronco-cefálico apresentaram similar proporção em ambas os grupos, em todas as faixas etárias; c) o comprimento dos membros inferiores foi superior no grupo das não atletas; Finalmente, pode-se concluir que o grupo das ginastas apresentou características de menor estatura em relação ao grupo das não atletas, e essa característica, aparentemente, não são definidas pelo treinamento sistemático.

\section{0 - CONTRIBUIÇÃO AUTONÔMICA E NÃO AUTONÔMICA PARA O AUTOMATISMO SINUSAL E PARA A CONDUÇÃO ATRIOVEN- TRICULAR EM ATLETAS}

Stein R., Medeiros C.M., Brozatto H., Zimerman L.I., Rosito G.A., Ribeiro J.P. Serviço de Cardiologia, HCPA, UFRGS - Porto Alegre - RS

Introdução: Atletas que executam atividades aeróbias apresentam maior prevalência de anormalidades na automaticidade atrial e na condução atrioventricular (AV) quando comparados com indivíduos não treinados. Dados prévios do nosso laboratório indicam que a atividade vagal aumentada explica parcialmente o atraso na condução AV encontrado em atletas altamente treinados (Stein et al. J Am Coll Cardiol 1998;31:156C). Objetivos: Testar a hipótese de que as alterações no automatismo sinusal e na condução AV em atletas são explicadas por adaptações relacionadas tanto ao sistema parassimpático quanto a adaptações intrínsecas (não autonômicas). Métodos: Seis atletas aerobicamente treinados e seis indivíduos saudáveis não treinados, todos do sexo masculino e com idades semelhantes, foram estudados. O consumo máximo de oxigênio $\left(\mathrm{VO}_{2}\right.$ max) foi avaliado através de teste ergoespirométrico. O tempo de recuperação do nó sinusal corrigido (TRNSc) e o ponto de Wenckebach (PW) foram avaliados através de estudo eletrofisiológico endocavitário. Todos os sujeitos foram sedados com midazolan endovenoso (EV) e as medidas eletrofisiológicas realizadas em um período basal, após a administração de $0.04 \mathrm{mg} / \mathrm{kg}$ EV de atropina, e após $0.2 \mathrm{mg} / \mathrm{kg}$ EV de propranolol. O teste não paramétrico de Student Newman Kuels para medidas repedidas foi utilizado para comparações. Resultados: $\mathrm{O} \mathrm{VO}_{2}$ max médio foi de $65 \mathrm{ml} / \mathrm{kg}$.min nos atletas e de $38 \mathrm{ml} / \mathrm{kg}$.min nos não atletas. O TRNSc foi mais alto nos atletas em todas as fases do experimento. Os atletas apresentaram PW em frequiências cardíacas mais baixas do que os não atletas nas três fases do estudo. Os valores medianos são descritos na tabela:

\begin{tabular}{|c|c|c|c|c|c|c|c|}
\hline & \multirow{2}{*}{$\begin{array}{l}\text { Tempo } \\
\text { corrigido } \\
\text { Basal }\end{array}$} & \multirow{2}{*}{$\begin{array}{l}\text { le recuperaşâे } \\
\text { Atropina }\end{array}$} & \multicolumn{2}{|c|}{ do nó sinusal } & \multicolumn{2}{|c|}{ Ponto de Wenckebach } & \multirow[b]{2}{*}{$\begin{array}{l}\text { Atropina } \\
\text { Propranolol }\end{array}+$} \\
\hline & & & $\begin{array}{l}\text { Atropina } \\
\text { Propranolol }\end{array}$ & & Basal & Atropina & \\
\hline $\begin{array}{l}\text { Atletas } \\
\text { Nâo atletas }\end{array}$ & $\begin{array}{l}382 \\
311 \\
\end{array}$ & $\begin{array}{l}203 \\
125 \\
\end{array}$ & $\begin{array}{l}200^{*} \\
170 \\
\end{array}$ & & $\begin{array}{l}585 * \\
427 \\
\end{array}$ & $\begin{array}{l}430 * \\
330\end{array}$ & $\begin{array}{l}493^{*} \\
405 \\
\end{array}$ \\
\hline
\end{tabular}


Conclusão: $\mathrm{O}$ automatismo sinusal foi reduzido e a condução AV apresentou atraso nos atletas independentemente do bloqueio parassimpático e do duplo bloqueio autonômico. Portanto, em adição aos efeitos vagais, o treinamento aeróbio de alta intensidade pode induzir adaptações intrínsecas no sistema excitocondutor, os quais podem contribuir para maior prevalência de anormalidades na condução $\mathrm{AV}$ em atletas (CNPq).

21 - INFLUÊNCIA DA ATIVIDADE FÍSICA REGULAR SOBRE VARIÁVEIS ANTROPOMÉTRICAS E NEUROMUSCULARES EM INDIVÍDUOS DO SEXO FEMININO NA TERCEIRA IDADE

Adriana Truccolo e Cíntia Vieira Marques

Universidade Luterana do Brasil (ULBRA) - Canoas - RS

Introdução: A expectativa de vida das mulheres vem aumentando com o passar dos anos (de 64.6 anos de idade em 1980 para 71.7 anos de idade em 2000), apontando para uma tendência populacional na Terceira Idade predominantemente feminina. Objetivo: Investigar os efeitos de um programa regular de atividade física sobre variáveis antropométricas e neuromusculares em mulheres na Terceira Idade. Material e Métodos: A coleta dos dados tem sido realizada no Laboratório de Fisiologia e Medicina Desportiva (LAFIMED) do curso de Educação Física da ULBRA. A amostra é composta por 20 indivíduos do sexo feminino que fazem parte do grupo ULBRATI. Antes de iniciar o programa as participantes realizam avaliação diagnóstica no laboratório que consiste em determinação de peso, estatura, composição corporal, flexibilidade, dinamometria e teste ergométrico. Somente após a realização dos testes, as mesmas iniciam o programa de atividade física que trabalha condicionamento cardiovascular, exercícios resistidos e relaxamento. Resultados: Os resultados observados no pré-teste demonstraram que a maioria das participantes estão com peso acima do considerado ideal para sexo e idade, flexibilidade e preensão manual fracas. Embora o comportamento eletrocardiográfico em esforço tenha sido considerado aceitável para a amostra participar do programa, foi evidenciada capacidade aeróbica de muito fraca a fraca na maioria das participantes. Conclusão: Acreditamos que após um ano de atividade física regular o grupo obterá, no pós-teste, resultados que sejam significativos e que demonstrem a eficácia de um programa de atividade física regular direcionado e elaborado para esta faixa etária, que tanto tem a ganhar com um estilo de vida saudável.

\section{2 - DISTRIBUIÇÃO DA PA ENTRE OS INDIVÍDUOS ADULTOS QUE PRATICAM ATIVIDADE FÍSICA NO GNU}

Norberto Martins, Renné Busnello, Helder Santos, Ivan Pacheco

Grêmio Náutico União - Porto Alegre - RS

Introdução: nos últimos anos, tem-se tentado estabelecer possíveis relações entre pressão arterial e diversos fatores e características populacionais. Objetivo: apresentar a distribuição da PA e sua relação com fatores como sexo, fumo, IMC, atividade física regular e faixa etária em adultos que praticam atividade física no GNU. Material e Métodos: foram analisados os dados de 956 casos de sócios submetidos ao exame de aptidão física. A medida da pressão arterial (PA) de repouso era realizada durante a entrevista inicial, onde, também, eram realizadas outras medidas: peso, altura, dobras cutâneas e frequiência cardíaca no repouso. Resultados: A média de PA sistólica foi $118,2 \pm 16,4 \mathrm{mmHg}$ e de PA diastólica $76,9 \pm 12,7 \mathrm{mmHg}$, em repouso. As médias de PA sistólica e diastólica no sexo masculino $(32,5 \%)$ foram significativamente mais altas em relação às do sexo feminino (PAS: $124,3 \pm 14,0$ vs $115,2 \pm 16,7$; PAD: $82,1 \pm 14,4$ vs $74,4 \pm 11,0 ; \mathrm{P}<0,05)$. Os sócios com história de fumo atualmente $(12 \%)$ tinham médias de PA sistólica e diastólica significativamente menores em relação aos não fumantes (PAS: $113 \pm 13,9$ vs $118,9 \pm 16,6$; PAD: $73,9 \pm 10,7$ vs $77,3 \pm 12,9$; P<0,05). Em relação ao índice de massa corporal, os que tinham IMC ${ }^{3} 25$ (37,8\%) tiveram médias de PA sistólica e diastólica significativamente maiores dos que os com IMC $<25$ (PAS $125,0 \pm 16,8$ vs $114,0 \pm 14,7$; PAD: $82,0 \pm 14,1$ vs $73,7 \pm 10,7$; $\mathrm{P}<0,05)$. Os que estavam praticando esporte regularmente $(40,5 \%)$ não mostraram diferença significativa nas médias de PA sistólica e diastólica em relação aos que não praticavam (PAS: 118,4 $\pm 16,1$ vs $118,0 \pm 16,6$; PAD: $76,6 \pm 12,5$ vs $77,0 \pm 12,9 ; \mathrm{P}<0,05$ ). O gráfico abaixo demonstra as médias de PA por faixa etária.

Distribuição da PA

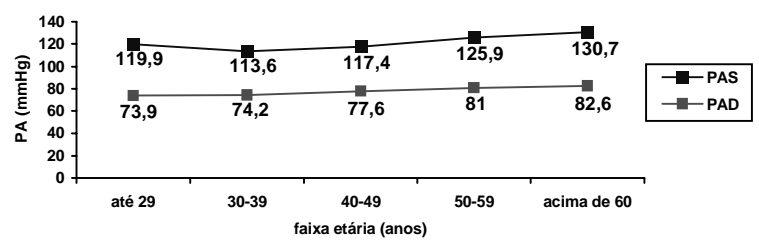

Conclusão: Encontramos uma PA sistólica significativamente mais alta nos indivíduos do sexo masculino. Também encontramos uma associação positiva entre IMC $>25$ e níveis médio de PA sistólica e diastólica mais elevados.

\section{3 - CARACTERÍSTICAS ANTROPOMÉTRICAS E DE APTIDÃO} FÍSICA EM PARTICIPANTES DE ATIVIDADES FÍSICAS NO GNU

Augusto Rafael Vargas, André Vargas, Rosemary Petkowicz, Helder Santos, Ivan Pacheco

Grêmio Náutico União - Porto Alegre - RS

Introdução: A conscientização da população em geral sobre a importância da pratica de atividades físicas regulares gerou um crescimento no número de pessoas que buscam sair da condição de sedentários para passar para o grupo dos fisicamente ativos Objetivos: Com o objetivo de descrever o perfil da população que pratica atividade física no Grêmio Náutico União (GNU), buscando caracterizar, nesta amostra, índices de aptidão física e composição corporal, bem como caracterizar os hábitos de atividade física, foi realizado o presente estudo. Material e Métodos: A amostra selecionada representa os indivíduos que, no período de um ano, abril 1999 até março 2000, inscreveram-se no GNU para iniciar a prática regular de exercícios. Rotineiramente, todos os inscritos em qualquer modalidade esportiva e que tenham idade acima de 30 anos devem realizar o Teste de Aptidão Física. Àqueles cuja idade é inferior a 30 anos o Teste é facultativo. O teste de Aptidão Física inclui anamnese, exame físico e avaliação da TA, avaliação da composição corporal e avaliação indireta do VO2. O método utilizado para quantificar a composição corporal é a equação de Faulkner modificada e a avaliação de VO2 indireto é realizada utilizando dois diferentes métodos, protocolos de Astrand e Bruce. Resultados: Durante este período foram avaliados 987 indivíduos, destes, $32,3 \%$ pertenciam ao sexo masculino e $67,7 \%$ ao sexo feminino. A idade média estratificada de acordo com o sexo a idade média foi 41,3 anos sexo masculino e 43,2 anos sexo feminino. Quanto a distribuição entre previamente ativos e sedentários, encontramos $40 \%$ dos indivíduos já realizavam alguma atividade física regular e $60 \%$ foram considerados sedentários, isto é, não realizavam nenhuma atividade física prévia. Musculação foi a modalidade mais procurada. Foram analisados os valores de VO2 médio de acordo com o tipo de teste realizado, Astrand ou Bruce, tendo sido encontrado os seguintes valores $26,93 \mathrm{ml} / \mathrm{kg}$.min e $33,10 \mathrm{ml} / \mathrm{kg}$.min, respectivamente. Na avaliação da composição corporal o grupo também foi estratificado conforme a faixa etária,sendo que os indivíduos pertencentes ao grupo idade superior 50 anos foram os que obtiveram maior percentual de gordura, 23,34 \%. Conclusões: Concluímos que há prevalência do grupo indivíduos previamente sedentários sobre o grupo que já realizava atividade física indicando possivelmente um maior número de pessoas que desejam deixar de ser sedentários.

\section{4 - AVALIAÇÃO DA MATURIDADE SEXUAL UTILIZANDO CRI- TÉRIOS DE TANNER}

Introdução: Tanner estabeleceu uma classificação baseando-se nos estágios de maturação sexual e o surgimento dos caracteres sexuais secundários a fim se poder reconhecer as etapas de desenvolvimento durante a adolescência. Entretanto, a necessidade de despir o paciente, para poder ser realizado o exame físico dos genitais, torna-se uma situação difícil e embaraçosa para o adolescente. Objetivos: Comparar a auto avaliação da maturidade sexual realizada pelos adolescentes com a avaliação realizada pelo médico utilizando o Método de Tanner. Material e Métodos: Este estudo foi realizado em atletas adolescentes das equipes de volei e natação do GNU. Sendo submetidos inicialmente a auto avaliação a partir dos diagramas de maturidade sexual de Tanner, na qual os jovens indicavam como se classificavam dentro destas escalas. Após a avaliação era realizada por um médico do mesmo sexo que o jovem avaliado. Os dados obtidos foram submetidos a análise estatística sendo utilizado o Coeficiente de Pearson. Resultados: Foram avaliados um total de 58 atletas, que estavam distribuídos $19 \%$ sexo masculino e $81 \%$ sexo feminino. A idade variou entre 10 e 15 anos, sendo idade média de 12,2 anos. A presença de menarca predominou em 76,6\% das meninas. Foi encontrado 60,8 \% de concodância entre a avaliação médica e das atletas sexo feminino na avaliação de $\mathrm{M}$ (mamas), na avaliação de $\mathrm{P}$ (pêlos) encontrou-se 63 \% de concordância entre médico e atletas sexo feminino (coeficiente de correlação de Pearson 0,867 para $\mathrm{M}$ e 0,650 para $\mathrm{P}$ ). Na avaliação dos atletas sexo masculino encontrou-se uma concordância de $63,3 \%$ para avaliação de $\mathrm{P}$ (pêlos) e de $81,1 \%$ para avaliação de $\mathrm{G}$ (genitália) entre a avaliação médica e auto avaliação (coeficiente de correlação de Pearson 0,653 para P e 0,802 para G). Conclusões: o uso da auto avaliação é um bom instrumento para avaliação da maturidade sexual em atletas.

25 - ANÁLISE DA COMPOSIÇÃO CORPORAL EM CRIANÇAS QUE PRATICAM A GINÁSTICA OLÍMPICA FEMININA

João Carlos Oliva, Rafael Reimann Baptista, Djan Drago e Maive Furman 
Universidade Luterana do Brasil - Porto Alegre - RS

O objetivo do estudo foi analisar variáveis de composição corporal em crianças, do sexo feminino. Os participantes foram selecionados de forma intencional e divididos em dois grupos: crianças que participaram do Campeonato Brasileiro de Ginástica Olímpica, nos anos de 1995, 1996 e 1997 (grupo de ginastas) e crianças que não praticaram nenhum esporte competitivo nos mesmos anos (grupo de não atletas). A metodologia utilizada foi desenvolvi-mentista com um delineamento transversal de comparação entre grupos. A composição corporal foi analisada mediante estimativa quanto à quantidade de gordura corporal e à massa magra. Para o tratamento estatístico das variáveis, recorreu-se ao teste " $\mathrm{t}$ " de Student para amostra independente, através do SPSS por Windows. Os resultados encontrados permitiram concluir que: a) Os indicadores da composição corporal revelaram resultados alternados nos valores médios de gordura corporal, entre os grupos, com uma tendência, de apresentar valores mais elevados para o grupo de não atletas; b) $\mathrm{O}$ componente endomorfo foi predominante no grupo de não atletas; c) $\mathrm{O}$ componente mesomorfo foi predominante no grupo das ginastas; d) não houve predominância do componente muscular em relação ao grupo das não atletas e essas características, aparentemente, não são definidas pelo treinamento sistemático.

\section{6 - AUTENTICIDADE CIENTÍFICA DO PLICÔMETRO CLÍNICO PARA AVALIAR OBESIDADE SEVERA}

Volmar Geraldo da Silva Nunes e Angelo José Rodrigues Mesa

Universidade Federal de Pelotas - Pelotas - RS

O propósito do estudo foi verificar a autenticidade científica do plicômetro clínico desenvolvido pelo Setor de Medidas e Avaliação (SMA) do Laboratório de Ensino, Pesquisa e Extensão (LEPE) da Escola Superior de Educação Física (ESEF) da Universidade Federal de Pelotas (UFPEL), para avaliar pessoas com obesidade severa de ambos os sexos. A classificou-se como obeso severo pessoas do sexo masculino com percentual de gordura corporal $(\% \mathrm{GC})^{3} 25 \%$ e para o sexo feminino ${ }^{3} 35 \%$. A autenticidade científica do plicômetro foi dada através do coeficiente de correlação linear de Pearson (r) entre as leituras das espessuras das dobras cutâneas do aparelho clínico desenvolvido pelo SMA/LEPE/ESEF/UFPEL e o da CESCORF. Na condição de obeso normal (sexo masculino ${ }^{3} 20 \%$ e sexo feminino ${ }^{3} 30 \%$ ) a validade preditiva obtevese um $\mathrm{r}=0,925$, a nível de $0,1 \%$, a fidedignidade através de teste e reteste foi de $\mathrm{r}=$ 0,998 , a nível de $0,1 \%$, e a objetividade (duas pessoas coletaram resultados simultâneos) foi de $r=0,976$, a nível de $0,1 \%$. Na condição de obeso severo não foi possível comparar os resultados pois o plicômetro clínico da CESCORF não avalia espessuras superiores a $70 \mathrm{~mm}$; enquanto que o desenvolvido pelo SMA/LEPE atinge o valor de $120 \mathrm{~mm}$, obtendo-se desta forma valores de fidedignidade e objetividade semelhantes aos anteriores. Conclui-se que o plicômetro clínico desenvolvido pelo SMA/LEPE ESEF/UFPEL apresenta autenticidade científica para avaliar obesidade severa.

\section{7-AUTENTICIDADE CIENTÍFICA DO RECEPTOR DE FREQÜÊN- CIA CARDÍACA}

Volmar Geraldo da Silva Nunes e Angelo José Rodrigues Mesa

Universidade Federal de Pelotas - Pelotas - RS

O propósito do estudo foi verificar a autenticidade científica do receptor de freqüência cardíaca de esforço (FCE) desenvolvido pelo Setor de Medidas e Avaliação (SMA) do Laboratório de Ensino, Pesquisa e Extensão (LEPE) da Escola Superior de Educação Física (ESEF) da Universidade Federal de Pelotas (UFPEL), para avaliar a FCE dos praticantes de ambos os sexos que freqüentam os diversos programas do LEPE. Este receptor tem a capacidade de captar a frequiência cardíaca(FC) dos transmissores da marca Polar, cuja a finalidade é proporcionar aos praticantes um autocontrole da FC em atividade, uma vez que o mesmo encontra-se disponível em diversos pontos do salão de atividades. A autenticidade científica do receptor foi dada através do coeficiente de correlação linear de Pearson (r) entre as leituras do receptor desenvolvido pelo SMA/LEPE/ESEF/UFPEL e o modelo BEAT da Polar. Na validade preditiva obteve-se um $r=0,941$, a nível de $0,1 \%$, a fidedignidade através de teste e reteste foi de $r=0,974$, a nível de $0,1 \%$, e a objetividade (duas pessoas coletaram resultados simultâneos) foi de $r=1$, a nível de $0,1 \%$. Conclui-se que o receptor desenvolvido pelo SMA/LEPE ESEF/UFPEL apresenta autenticidade científica para avaliar a FCE.

28 - ENERGY COST OF WALKING IN ADOLESCENT BOYS WHO DIFFER IN ADIPOSITY LEVEL AND DISTRIBUTION BUT ARE MATCHED FOR TOTAL BODY MASS

Beatriz Volpe Ayub and Oded Bar-Or

McMaster University, Hamilton, ON, Canada

Energy cost of walking is higher for heavier people than for lighter ones. We compared adolescents who were matched for total body mass but had different body composition, with the intention of verifying the influence of body fat per se on the energy cost of walking. Nine pairs of boys $(16.37 \pm 1.57$ years and $12.90 \pm 1.49$ years for the lean and the obese, respectively) took part. Metabolic energy expenditure (EE) was compared during treadmill walks at 4, 5 and $6 \mathrm{kph}$. Fat mass and distribution were assessed by whole body dual-energy x-ray absorptiometry. A repeated measure ANOVA was performed to compare the matched pairs. Based on multiple regression, pooling all subjects together, the variance explained by adiposity increased with increasing speed. However, there was no influence of the distribution of fat on the EE, even though the obese tended to spend more energy than their lean pairs at the two fastest walking speeds $(9.44 \pm 0.95$ and $13.19 \pm 1.92 \mathrm{ml} / \mathrm{kg}$.min at 5 and $6 \mathrm{kph}$ respectively for the lean subjects, and $9.96 \pm 1.05$ and $14.43 \pm 1.39 \mathrm{ml} / \mathrm{kg}$.min for the obese subjects - values show Mean \pm SD). Although the total mass in the legs, arms and trunk was similiar for both groups, the obese subjects had significanlty more fat than the lean group in each body segment $(\mathrm{p}<0.01)$. There was no relationship between EE and segmental fat content. We conclude that neither total body fatness per se nor the amount of fat in the limbs affect the energy cost of walking at those three walking speeds. 